\title{
Modeling the complete cardiac ganglion - heart muscle network of the crab Callinectes sapidus
} Estee Stern*1, Keyla García-Crescioni², Mark W Miller ${ }^{2}$, Charles S Peskin ${ }^{3}$ and Vladimir Brezina ${ }^{1}$

\author{
Address: ${ }^{1}$ Department of Neuroscience, Mount Sinai School of Medicine, New York, NY, USA, ${ }^{2}$ Institute of Neurobiology, University of Puerto \\ Rico Medical Sciences Campus, San Juan, PR, USA and ${ }^{3}$ Courant Institute of Mathematical Sciences and Center for Neural Science, New York \\ University, New York, NY, USA \\ Email: Estee Stern* - estee.stern@mssm.edu \\ * Corresponding author
}

from Eighteenth Annual Computational Neuroscience Meeting: CNS*2009

Berlin, Germany. 18-23 July 2009

Published: 13 July 2009

BMC Neuroscience 2009, I 0(SuppI I):P295 doi:I0.I I86/I47|-2202-I0-SI-P295

This abstract is available from: http://www.biomedcentral.com/I47I-2202/I0/SI/P295

(c) 2009 Stern et al; licensee BioMed Central Ltd.

In the neurogenic heart of the blue crab, Callinectes sapidus $[1]$, the cardiac ganglion (CG) and the heart muscle form a closed-loop network. Spikes generated by the CG drive contractions of the muscle, which in turn provide feedback to the CG to modify its future spiking. We have modeled the activity of the whole network at the level of the spikes and contractions. At this level, the network can be regarded as composed of three processes (arrows in Fig. $1 A)$ : (1) the production of the contractions by the CG spikes, (2) the feedback from the contractions back to the CG, and (3) the endogenous spiking of the CG itself. We first characterized each process separately from experimental data, using a decoding method that we developed for this purpose [2]. For process (1), we obtained three elementary functions to describe the transform from spikes to contractions: $K$, the single-spike contraction response kernel; $H$, a history kernel; and $F$, a static nonlinear function. These three functions were able to successfully predict the contraction response to arbitrary spike trains $[3,4]$. For processes (2) and (3), we used a modified version of the same decoding method to find three further elementary functions: $H^{\prime}$, a history kernel that describes the endogenous spike generation by the $\mathrm{CG}$, that is, the probability of generating a spike given the previous history of spiking; $K^{\prime}$, a feedback kernel that describes the probability of spiking given the previous history of contraction; and $F^{\prime}$, a static nonlinear function [5]. We then combined the six elementary functions in a generative model of the complete system implemented in a simulator in MATLAB. The model generates, from the spikes and contractions up to any given time, the next spike and con-
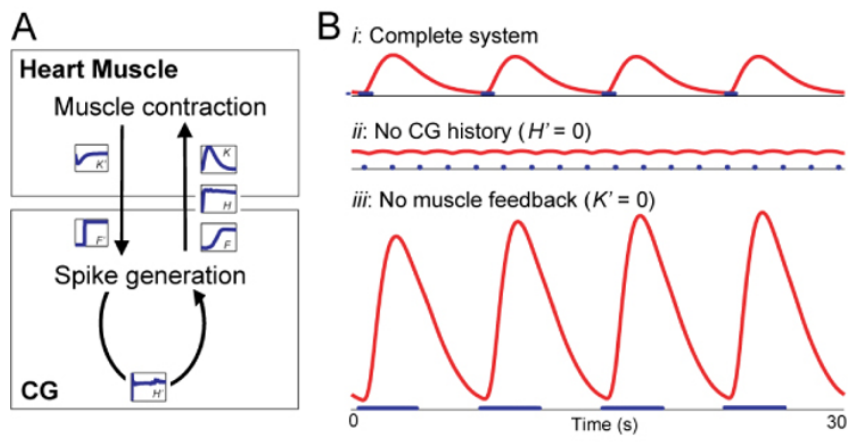

\section{Figure I}

The crab cardiac system model and its behavior. A: the three processes (arrows) and the six elementary functions (shown in semi-cartoon form) that describe them. $B$ : representative sections of spikes (blue) and contractions (red) produced when the model was run with all six elementary functions intact (i), with the CG history kernel disabled $\left(H^{\prime}=0\right.$; ii), and with the feedback from the muscle disabled $\left(K^{\prime}=0 ; i i\right)$. 
traction. The computation is purely local in time: no longrange dynamics or oscillatory phenomena such as spike bursts are explicitly represented. Nevertheless, the model, like the real system, produces robust spike bursts and corresponding phasic muscle contractions (Fig. 1B, i). In fact, it does so by two distinct mechanims: the central process (3) and the peripheral feeback loop composed of processes (1) and (2). Either mechanism can generate bursts and phasic contractions alone if the other mechanism is disabled (Figure $B, i i, i i i$ ). We are now using the simulator to further explore the behavior of the system and to make predictions that will be experimentally testable in the real system.

\section{Acknowledgements}

Supported by NIH grants NS0580 I7, NS4 I 497, GM08224, and RR0305I.

\section{References}

I. Cooke IM: Reliable, responsive pacemaking and pattern generation with minimal cell numbers: the crustacean cardiac ganglion. Biol Bull 2002, 202:108-136.

2. Stern E, Fort TJ, Miller MW, Peskin CS, Brezina V: Decoding neurophysiological responses to arbitrary spike trains. Soc Neurosci Abstr 2006. 491.7.

3. Stern E, Fort TJ, Miller MW, Peskin CS, Brezina V: Decoding modulation of the neuromuscular transform. Neurocomputing 2007, 70: $1753-1758$.

4. Stern E, Fort TJ, Miller MW, Peskin CS, Brezina V: Characterization of the crab cardiac neuromuscular transform. Soc Neurosci Abstr 2007. 536.I.

5. Brezina V, Stern E, Lifland AW, García-Crescioni K, Fort TJ, Miller MW, Peskin CS: Decoding of simple kernel-based spike train models. Soc Neurosci Abstr 2008. 695.14
Publish with Biomed Central and every scientist can read your work free of charge

"BioMed Central will be the most significant development for disseminating the results of biomedical research in our lifetime."

Sir Paul Nurse, Cancer Research UK

Your research papers will be:

- available free of charge to the entire biomedical community

- peer reviewed and published immediately upon acceptance

- cited in PubMed and archived on PubMed Central

- yours - you keep the copyright

Submit your manuscript here:

http://www.biomedcentral.com/info/publishing_adv.asp 